\title{
Hematopoietic cell transplantation for asymptomatic X-linked lymphoproliferative syndrome type 1
}

\author{
Akihiro Tamura $^{1 *}$ (D), Suguru Uemura ${ }^{1,2}$, Nobuyuki Yamamoto ${ }^{1}$, Atsuro Saito ${ }^{1}$, Aiko Kozaki ${ }^{1}$, Kenji Kishimoto ${ }^{1}$, \\ Toshiaki Ishida', Daiichiro Hasegawa' ${ }^{1}$, Haruka Hiroki ${ }^{3}$, Tsubasa Okano ${ }^{3}$, Kohsuke Imai ${ }^{4}$, Tomohiro Morio ${ }^{3}$, \\ Hirokazu Kanegane ${ }^{5}$ and Yoshiyuki Kosaka ${ }^{1}$
}

\begin{abstract}
Background: X-linked lymphoproliferative disease type 1 (XLP1) is a rare primary immune deficiency, which is caused by SH2D1A gene mutations. XLP1 is commonly associated with Epstein-Barr virus (EBV)-associated hemophagocytic lymphohistiocytosis, hypogammaglobulinemia, and/or lymphoma. The only curative treatment for XLP1 is allogeneic hematopoietic cell transplantation. However, published data detailing the clinical course of, and indications for, allogeneic hematopoietic cell transplantation in asymptomatic patients with XLP1 is lacking. Although relevant family history could be useful in identifying patients with XLP1 before disease onset, no guidelines have been established on the management of asymptomatic patients with XLP1. Therefore, clinicians and families face dilemmas in balancing between the risk of waiting for the disease onset, and the risk of transplant-related mortality associated with allogeneic hematopoietic cell transplantation, which is often performed at a very young age. We first describe the detailed clinical course of an asymptomatic patient with XLP1 who successfully underwent allogeneic hematopoietic cell transplantation.
\end{abstract}

Case presentation: A boy was born at 39 weeks of gestation, weighing $3016 \mathrm{~g}$ at birth. He appeared fine, but he underwent genetic testing because his maternal cousin had XLP1. He was found to have a novel c.207_208insC (p.Pro70ProfsX4) mutation in exon 3 of SH2D1A, which was also found in his cousin. There was no HLA-identical donor in his family. Immunoglobulin was administered monthly to prevent EBV infection while searching for an alternative donor. He underwent allogeneic bone marrow transplantation (BMT) from an allele HLA 8/8 fully matched, unrelated donor with a reduced-intensity conditioning $(\mathrm{RIC})$ regimen consisting of fludarabine, melphalan, and low-dose total body irradiation (TBI) at 20 months of age. The patient has been doing well for 2 years post transplantation and maintaining complete donor chimerism without any evidence of chronic graft versus host disease.

Conclusions: We describe a case of an asymptomatic patient with XLP1, who successfully underwent unrelated BMT with RIC regimen consisting of fludarabine, melphalan, and 3 Gy TBI. That was well tolerated and successfully generated complete chimerism in every subpopulation. This case delineates the option of allogeneic hematopoietic cell transplantation even in asymptomatic patients with XLP1.

Keywords: Hematopoietic cell transplantation, Asymptomatic, X-linked lymphoproliferative disease type 1

\footnotetext{
*Correspondence: tamura_kch@hp.pref.hyogo.jp

1 Department of Hematology and Oncology, Children's Cancer Center

Kobe Children's Hospital, Minatojima-Minamimachi 1-6-7, Chuo-ku,

Kobe 650-0047, Japan

Full list of author information is available at the end of the article
} 


\section{Background}

$\mathrm{X}$-linked lymphoproliferative disease type 1 (XLP1) is a rare primary immune deficiency that affects one in 1 million boys $[1,2]$. XLP1 is caused by mutations in the $S H 2 D 1 A$ gene that encodes the signaling lymphocytic activation molecule-associated protein (SAP) and is located on Xq25 [3]. SAP modulates intracellular signal transduction via its association with the SLAM family [4]. To date, more than $70 S H 2 D 1 A$ mutations have been reported with inconsistent genotype-phenotype correlation, which can vary even amongst family members who share the same mutation $[2,5]$. XLP1 is commonly associated with Epstein-Barr virus (EBV)associated hemophagocytic lymphohistiocytosis (HLH), hypogammaglobulinemia, and/or lymphoma [6, 7].

The only curative treatment for XLP1 is allogeneic hematopoietic cell transplantation (HCT). However, performing HCT after lymphoproliferation results in suboptimal outcomes [8]. Although relevant family history could be useful in identifying patients affected with XLP1 before disease onset, there are no guidelines on the management of asymptomatic patients with XLP1. Furthermore, no published data detail the clinical course of, and indications for, HCT for asymptomatic patients with XLP1. Therefore, clinicians and families face dilemmas in balancing between the risk of waiting for the disease onset, and the risk of treatment related mortality associated with allogeneic hematopoietic cell transplantation, which is often performed at a very young age. Furthermore, the optimal pretransplant conditioning regimen for XLP1 has not yet been established.

Here, we detail the clinical course of an asymptomatic patient with XLP1 with a novel c.207_208insC (p.Pro70ProfsX4) mutation in $S H 2 D 1 A$ who successfully underwent allogeneic $\mathrm{HCT}$ with a reduced-intensity conditioning (RIC) regimen.

\section{Methods}

SH2D1A mutation was detected by direct sequencing as previously described [9]. SAP protein expressions were assessed by flow cytometry as previously reported [10-13].

\section{Case presentation}

A boy was born at 39 weeks of gestation, weighing $3016 \mathrm{~g}$ at birth. He appeared fine, but he underwent genetic testing because his maternal cousin had XLP1, and he was found to have a c.207_208insC (p.Pro70ProfsX4) mutation in exon 3 of $S H 2 D 1 A$ (Fig. 1a, upper panel), which was the same mutation as that carried by his

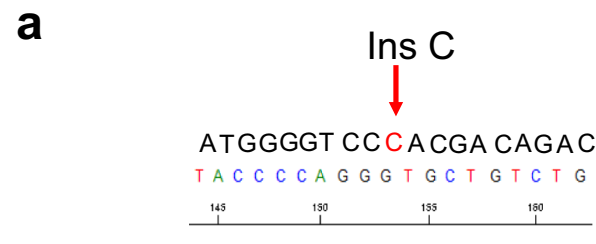

Patient

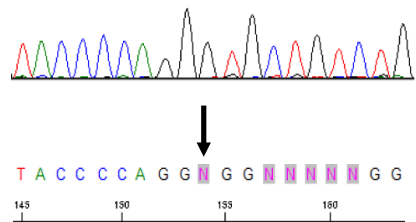

Mother
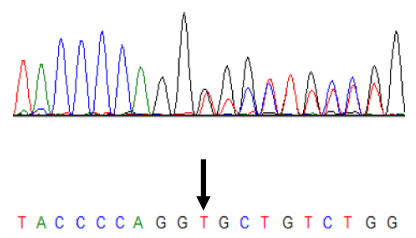

150

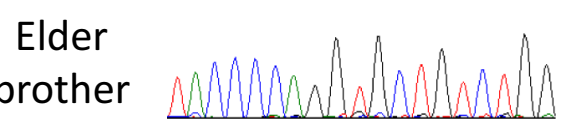

b CD8 ${ }^{+} \mathrm{T}$ cells $\quad \mathrm{CD}^{2} 6^{+} \mathrm{NK}$ cells
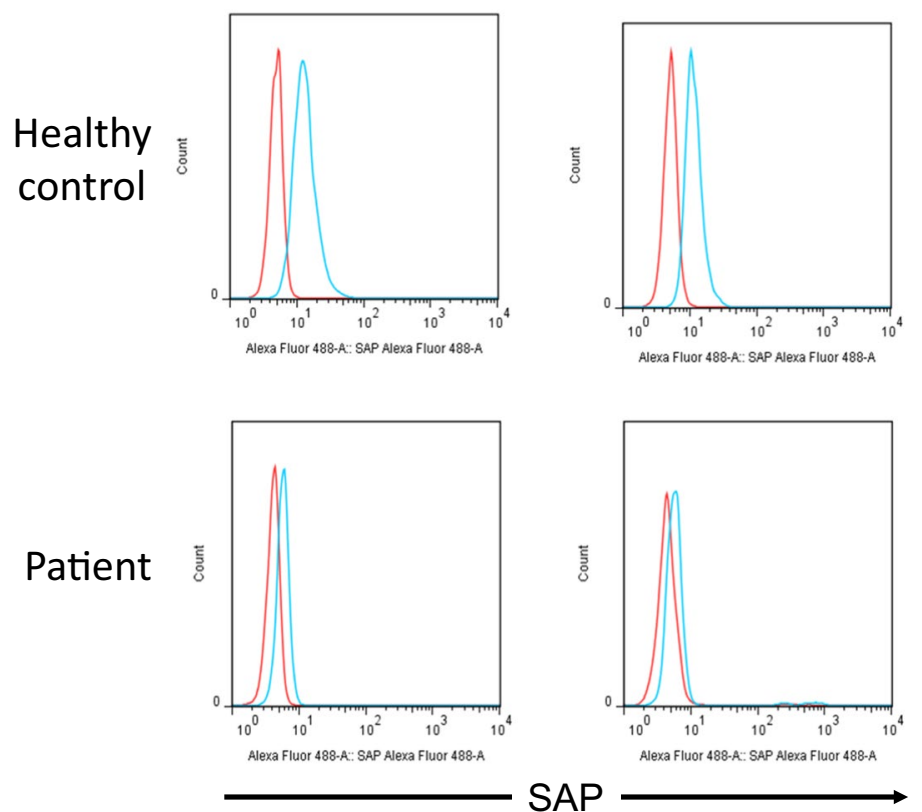

SAP

Fig. 1 a Mutation analysis of XLP1 family. Direct sequencing analysis of the SH2D1A gene revealed c.207_208insC in the patient (upper panel). His mother showed a heterozygous mutation, indicating a carrier, whereas his elder brother showed a wild allele, indicating a normal (middle and lower panels). Arrows indicate the mutation site. b Flow cytometric analysis of SAP expression. Intracellular SAP expression in CD8 ${ }^{+} \mathrm{T}$ cells and $\mathrm{CD} 6^{+} \mathrm{NK}$ cells was reduced in the patient. Red line, isotype control; blue line, anti-SAP monoclonal antibody 
cousin. Gene analysis revealed that his mother was a carrier, and his elder brother was healthy (Fig. 1a, middle and lower panels). c.207_208insC in SH2D1A identified in this family was a novel mutation. SAP protein expressions assessed by flow cytometry were reduced both in $\mathrm{CD}^{+} \mathrm{T}$ cells and $\mathrm{CD}^{+} 6^{+} \mathrm{NK}$ cells (Fig. 1b). Serum immunoglobulin levels were of $275 \mathrm{mg} / \mathrm{dL}, 19 \mathrm{mg} /$ $\mathrm{dL}$, and $61 \mathrm{mg} / \mathrm{dL}$ for IgG, IgA, and IgM, respectively, at 6 months of age, which were within normal range for infants of this age [14]. There was no HLA-identical HCT donor in his family. Immunoglobulin was administered monthly to prevent EBV infection, although the utility of such prophylaxis has not been demonstrated. He was admitted to our hospital for allogeneic bone marrow transplantation (BMT) at 20 months of age. Blood cell and differential counts were within normal ranges with a white blood cell count of $9.6 \times 10^{9} / \mathrm{L}$ ( $20.5 \%$ neutrophils, $1.5 \%$ eosinophils, $0.5 \%$ basophils, $4.0 \%$ monocytes, and $73.5 \%$ lymphocytes), a hemoglobin level of $9.7 \mathrm{~g} / \mathrm{dL}$, and a platelet count of $429 \times 10^{9} / \mathrm{L}$. Flow cytometric analysis of peripheral blood lymphocyte subsets revealed the following: $\mathrm{CD}^{+} \mathrm{T}$ cells: $57.0 \%$; $\mathrm{CD}^{+} \mathrm{T}$ cells: $38.3 \%$; $\mathrm{CD}^{+} \mathrm{T}$ cells: $20.8 \% ; \mathrm{CD} 4 / \mathrm{CD} 8=1.84 ; \mathrm{CD}{ }^{+} \mathrm{B}$ cells 9.2\%; and $\mathrm{CD}^{2} 6^{+} \mathrm{CD}^{-}$NK cells $4.8 \%$. NK cytotoxicity activity was assessed using $\mathrm{Cr}^{51}$ release assay, which was normal at $51.1 \%$. The result of the phytohemagglutinin stimulation test was within the normal range. Our patient underwent allogeneic BMT from an allele HLA 8/8 fully matched, unrelated donor. The conditioning regimen consisted of the administration of $30 \mathrm{mg} / \mathrm{m}^{2}$ fludarabine for 5 days (days- $8,-7,-6,-5,-4), 70 \mathrm{mg} / \mathrm{m}^{2}$ melphalan for 2 days (days-3, -2), and 3 Gy TBI (day-1). Graft versus host disease (GVHD) prophylaxis consisted of tacrolimus and short-term methotrexate. Engraftment of neutrophil was achieved on day 17. The patient developed acute GVHD grade I (skin stage 1), which spontaneously resolved over the clinical course. The patient had transient asymptomatic cytomegalovirus and aspergillus antigenemia. Otherwise, the BMT was uncomplicated.
Chimerism analysis assessed by the recently developed mutation-specific droplet digital PCR showed more than 99\% of donor type in every subpopulation (whole blood cells, peripheral blood mononuclear cells, granulocytes, $\mathrm{T}$ cells, and NK cells) as we recently reported [15]. He has been doing well for 2 years post transplantation and maintaining complete donor chimerism without any evidence of chronic GVHD.

\section{Discussion and conclusions}

Here, we describe a case of an asymptomatic patient with XLP1 with c.207_208insC mutation, who successfully underwent unrelated BMT with RIC regimen consisting of fludarabine, melphalan, and 3 Gy TBI. A recent international retrospective study showed an excellent survival rate $(93 \% ; 15$ out of 16$)$ in asymptomatic patients with primary HLH (PRF1, STXBP2, UNC13D, STX11, $R A B 27 A$, and LYST deficiency) treated with HCT [16]. Asymptomatic patients with XLP1 would have better HCT outcome as well as those with primary HLH. In the largest retrospective analysis of transplantation for XLP1, all patients who underwent allogeneic HCT before the onset of HLH survived (27 out of 27), whereas patients who underwent HCT after HLH onset resulted in decreased survival rate of 50\% [8]. Even in the largest retrospective study, indications for HCT, besides $\mathrm{HLH}$, were lymphoma and/or dysgammaglobulinemia [8]. It is not clear whether asymptomatic patients underwent HCT as part of this study [8]. Two asymptomatic patients with XLP1 underwent HCT in Japan previously; however, the detailed clinical information is lacking for the two other Japanese asymptomatic patients with XLP1 [5] (Table 1). Despite variable conditioning regimens, all three patients including our patient survived without chronic GVHD (Table 1). The prognosis of patients with XLP1 not undergoing HCT is poor [8]. In contrast, the prognosis is good in patients with XLP1 who undergo HCT before disease onset. Therefore, we suggest that

Table 1 HCT for asymptomatic patients with XLP1

\begin{tabular}{|c|c|c|c|c|c|c|c|c|}
\hline Age & $\begin{array}{l}\text { Donor } \\
\text { Source }\end{array}$ & HLA matching & Conditioning regimen & GVHD prophylaxis & aGVHD & cGVHD & Outcome & References \\
\hline 1 years & $\begin{array}{l}\text { Unrelated } \\
\text { BM }\end{array}$ & $6 / 6$ & Bu/TAl 3 Gy/Flu/CY/ATG & Tacrolimus/sMTX & None & None & Alive (3 years) & {$[5]$} \\
\hline 8 months & $\begin{array}{l}\text { Unrelated } \\
\text { PBSC }\end{array}$ & $5 / 6$ & Flu/Mel/ATG/TAI 6 Gy & Tacrolimus/sMTX/PSL & Gradell & None & Alive (9 years) & {$[5]$} \\
\hline 20 months & $\begin{array}{l}\text { Unrelated } \\
\text { BM }\end{array}$ & $8 / 8$ & Flu/Mel/TBI 3 Gy & Tacrolimus/sMTX & Gradel & None & Alive (2 years) & Our patient \\
\hline
\end{tabular}

aGVHD acute graft versus host disease, $A T G$ anti thymocyte globulin, $B M$ bone marrow, $B u$ busulfan, $C G V H D$ chronic graft versus host disease, $C Y$ cyclophosphamide, Flu fludarabine, Mel melphalan, PBSC peripheral blood stem cells, PSL prednisolone, SMTX short term methotrexate, TAI total abdominal irradiation, TBI total body irradiation 
Table 2 Flu/Mel/TBI 3 Gy conditioning HCT for XLP1 in Japan

\begin{tabular}{|c|c|c|c|c|c|c|c|c|}
\hline Age & Symptoms & $\begin{array}{l}\text { Donor } \\
\text { Source }\end{array}$ & HLA matching & GVHD prophylaxis & aGVHD & cGVHD & Outcome & References \\
\hline 3 years & HLH, hypo- $\gamma$ & $\begin{array}{l}\text { Unrelated } \\
\text { BM }\end{array}$ & $4 / 6$ & Tacrolimus/sMTX & Grade I & None & Alive (8 years) & {$[5]$} \\
\hline 7 years & Нуро- $\gamma$ & $\begin{array}{l}\text { Unrelated } \\
\text { BM }\end{array}$ & $6 / 6$ & Tacrolimus/sMTX & None & Extensive & Alive (4 years) & {$[5]$} \\
\hline 15 years & HLH, ML, hypo- $\gamma$ & $\begin{array}{l}\text { Unrelated } \\
\text { BM }\end{array}$ & $6 / 6$ & Tacrolimus/sMTX & None & None & Alive (3 years) & {$[5]$} \\
\hline 20 months & Asymptomatic & $\begin{array}{l}\text { Unrelated } \\
\text { BM }\end{array}$ & $8 / 8$ & Tacrolimus/sMTX & Grade I & None & Alive (2 years) & Our patient \\
\hline
\end{tabular}

HLH hemophagocytic lymphohistiocytosis, hypo- $\gamma$ hypo gammaglobulinemia

HCT should be performed even in asymptomatic patients.

Furthermore, the optimal pretransplant conditioning regimen for XLP1 has not yet been established because the number of patients with XLP1 is limited. Historically, most patients with XLP1 have been transplanted using myeloablative-conditioning regimens [17]. Recently, a RIC regimen has been used to reduce therapy-related mortality and late sequelae [5, 17]. Marsh et al. [18] reported promising results with a $75 \%$ (12 of 16) survival rate in the treatment of patients with XLP1 with a RIC regimen consisting of alemtuzumab, fludarabine, and melphalan. However, in this study, a high rate of mixed chimerism (5 of 16 patients) and infections (3 of 4 deaths attributed to infectious complications) are noted [18]. In our patient, complete chimerism (>99\%) for every subpopulation was confirmed using the recently developed mutation-specific droplet digital PCR [15]. In Japan, 11 of 12 patients (92\%) with XLP1 who underwent $\mathrm{HCT}$ with various conditioning regimens survived [5]. In this previous report, three patients underwent transplantation with RIC regimen consisting of fludarabine, melphalan, and low-dose TBI, and all patients are alive (Table 2). Alemtuzumab is not approved in the setting of pretransplant conditioning in Japan and in many other countries; therefore, fludarabine, melphalan, and low-dose TBI can be a good candidate for conditioning regimen for XLP1. Further clinical studies are required to establish optimal strategy of transplantation for patients with XLP1.

\section{Abbreviations \\ XLP1: X-linked lymphoproliferative disease type 1; SAP: signaling lymphocytic activation molecule-associated protein; EBV: Epstein-Barr virus; HLH: hemophagocytic lymphohistiocytosis; HCT: hematopoietic cell transplantation; RIC: reduced-intensity conditioning; TBI: total body irradiation; BMT: bone marrow transplantation; GVHD: graft versus host disease.}

\section{Authors' contributions}

AT provided medical care, interpreted data, and drafted manuscript. SU, NY, $\mathrm{AS}, \mathrm{AK}, \mathrm{KK}$, and TI provided medical care and critical discussion. $\mathrm{HH}, \mathrm{TO}, \mathrm{KI}, \mathrm{TM}$, and HK analyzed gene mutation, provided critical suggestion, and drafted manuscript. DH and YK provided medical care and supervised management of the patient. All authors read and approved the final manuscript.

\section{Author details \\ ${ }^{1}$ Department of Hematology and Oncology, Children's Cancer Center, Kobe Children's Hospital, Minatojima-Minamimachi 1-6-7, Chuo-ku, Kobe 650-0047, Japan. ${ }^{2}$ Department of Pediatrics, Graduate School of Medicine, Kobe University Hospital, Kusunoki-cho 7-5-2, Chuo-ku, Kobe 650-0017, Japan. ${ }^{3}$ Department of Pediatrics and Developmental Biology, Graduate School of Medical and Dental Sciences, Tokyo Medical and Dental University, Yushima 1-5-45, Bunkyo-ku, Tokyo 113-8519, Japan. ${ }^{4}$ Department of Community Pediatrics, Perinatal and Maternal Medicine, Graduate School of Medical and Dental Sciences, Tokyo Medical and Dental University, Yushima 1-5-45, Bunkyo-ku, Tokyo 113-8519, Japan. ${ }^{5}$ Department of Child Health and Development, Graduate School of Medical and Dental Sciences, Tokyo Medical and Dental University, Yushima 1-5-45, Bunkyo-ku, Tokyo 113-8519, Japan.}

\section{Acknowledgements}

Not applicable.

\section{Competing interests}

The authors declare that they have no competing interests.

\section{Availability of data and materials}

All data is stored and available in the patient's medical records and may be requested to see a copy at any stage.

\section{Consent for publication}

Written and oral informed consent for publication was obtained from the patient's guardians and stored in the medical records and may be requested to see a copy at any stage.

\section{Ethics approval and consent to participate}

Written and oral informed consent was obtained from the patient's guardians with regard to conducting genetic analysis. The study was approved by the Ethics Committee on Medical Research of Tokyo Medical and Dental University and carried out on the basis of the declaration of Helsinki.

\section{Funding}

This study was supported by grants from the Ministry of Education, Culture, Sports, Science, and Technology of Japan, and the Ministry of Health, Labor, and Welfare of Japan.

\section{Publisher's Note}

Springer Nature remains neutral with regard to jurisdictional claims in published maps and institutional affiliations.

Received: 27 May 2018 Accepted: 2 November 2018

Published online: 14 November 2018 


\section{References}

1. Purtilo DT, Grierson HL. Methods of detection of new families with X-linked lymphoproliferative disease. Cancer Genet Cytogenet. 1991;51:143-53.

2. Sumegi J, Huang D, Lanyi A, Davis JD, Seemayer TA, Maeda A, et al. Correlation of mutations of the SH2D1A gene and Epstein-Barr virus infection with clinical phenotype and outcome in X-linked lymphoproliferative disease. Blood. 2000;96:3118-25.

3. Sayos J, Wu C, Morra M, Wang N, Zhang X, Allen D, et al. The X-linked lymphoproliferative-disease gene product SAP regulates signals induced through the co-receptor SLAM. Nature. 1998;395:462-9.

4. Latour S, Roncagalli R, Chen R, Bakinowski M, Shi X, Schwartzberg PL, et al. Binding of SAP SH2 domain to FynT SH3 domain reveals a novel mechanism of receptor signalling in immune regulation. Nat Cell Biol. 2003;5:149-54.

5. Kanegane $H$, Yang $X$, Zhao M, Yamato K, Inoue $M$, Hamamoto $K$, et al. Clinical features and outcome of X-linked lymphoproliferative syndrome type 1 (SAP deficiency) in Japan identified by the combination of flow cytometric assay and genetic analysis. Pediatr Allergy Immunol. 2012:23:488-93.

6. Rezaei N, Mahmoudi E, Aghamohammadi A, Das R, Nichols KE. X-linked lymphoproliferative syndrome: a genetic condition typified by the triad of infection, immunodeficiency and lymphoma. Br J Haematol. 2011;152:13-30.

7. Panchal N, Booth C, Cannons JL, Schwartzberg PL. X-linked lymphoproliferative disease type 1: a clinical and molecular perspective. Front Immunol. 2018:9:666.

8. Booth C, Gilmour KC, Veys P, Gennery AR, Slatter MA, Chapel H, et al. X-linked lymphoproliferative disease due to SAP/SH2D1A deficiency: a multicenter study on the manifestations, management and outcome of disease. Blood. 2011;117:53-62.

9. Sumazaki R, Kanegane H, Osaki M, Fukushima T, Tsuchida M, Matsukura $\mathrm{H}$, et al. SH2D1A mutations in Japanese males with severe Epstein-Barr virus-associated illnesses. Blood. 2001;98:1268-70.
10. Okano H, Nishikawa T, Watanabe E, Watanabe T, Takashima T, Yeh TW, et al. Maternal $T$ and $B$ cell engraftment in two cases of $X$-linked severe combined immunodeficiency with IgG gammopathy. Clin Immunol. 2017; 183:112-20

11. Tabata Y, Villanueva J, Lee SM, Zhang K, Kanegane H, Miyawaki T, et al. Rapid detection of intracellular SH2D1A protein in cytotoxic lymphocytes from patients with X-linked lymphoproliferative disease and their family members. Blood. 2005;105:3066-71.

12. Zhao M, Kanegane H, Kobayashi C, Nakazawa Y, Ishii E, Kasai M, et al. Early and rapid detection of X-linked lymphoproliferative syndrome with SH2D1A mutations by flow cytometry. Cytom B Clin Cytom. 2011;80:8-13.

13. Kanegane $\mathrm{H}$, Hoshino A, Okano T, Yasumi T, Wada T, Takada H, et al. Flow cytometry-based diagnosis of primary immunodeficiency diseases. Allergol Int. 2018;67:43-54.

14. Agarwal S, Cunningham-Rundles C. Assessment and clinical interpretation of reduced lgG values. Ann Allergy Asthma Immunol. 2007:99(3):281-3.

15. Okano T, Tsujita Y, Kanegane H, Mitsui-Sekitani K, Tanita K, Miyamoto $\mathrm{S}$, et al. Droplet digital PCR-based chimerism analysis for primary immunodeficiency diseases. J Clin Immunol. 2018;38:300-6.

16. Lucchini G, Marsh R, Gilmour K, Worth A, Nademi Z, Rao A, et al. Treatment dilemmas in asymptomatic children with primary haemophagocytic lymphohistiocytosis. Blood. 2018. https://doi. org/10.1182/blood-2018-01-827485.

17. Lankester AC, Visser LF, Hartwig NG, Bredius RG, Gaspar HB, van der Burg $M$, et al. Allogeneic stem cell transplantation in X-linked lymphoproliferative disease: two cases in one family and review of the literature. Bone Marrow Transplant. 2005;36:99-105.

18. Marsh RA, Bleesing JJ, Chandrakasan S, Jordan MB, Davies SM, Filipovich $\mathrm{AH}$. Reduced-intensity conditioning hematopoietic cell transplantation is an effective treatment for patients with SLAM-associated protein deficiency/X-linked lymphoproliferative disease type 1. Biol Blood Marrow Transplant. 2014;20:1641-5.
Ready to submit your research? Choose BMC and benefit from:

- fast, convenient online submission

- thorough peer review by experienced researchers in your field

- rapid publication on acceptance

- support for research data, including large and complex data types

- gold Open Access which fosters wider collaboration and increased citations

- maximum visibility for your research: over $100 \mathrm{M}$ website views per year

At $\mathrm{BMC}$, research is always in progress.

Learn more biomedcentral.com/submissions 